\title{
ASSISTÊNCIA TÉCNICA E EXTENSÃO RURAL NO BRASIL: UMA ANÁLISE DO CENSO AGROPECUÁRO DE 2017
}

\author{
Caroline Nascimento Pereira ${ }^{2}$
}

César Nunes de Castro ${ }^{3}$

\section{INTRODUÇÃO}

Durante muitos anos a agricultura foi realizada de forma rudimentar, com baixo uso de inovações tecnológicas. Decorrente em grande parte da vasta extensão territorial, que permitia expandir a produção constantemente, e da contida demanda observada antes da industrialização brasileira, o país alterou um pouco sua base produtiva, e por volta dos anos 1960 parte da população migrava para as cidades, e o campo se tornava um espaço estratégico para fornecimento de alimentos e matérias-primas (Vieira Filho e Fishlow, 2017).

A necessidade de mudanças se fez premente no meio do século XX, e alteraçōes na forma como se produzia começaram, gradativamente, a ser implementadas. A Revoluçáo Verde foi introduzida no Brasil por volta dos anos 1960 e por meio dela incorporaram-se insumos agrícolas, como máquinas, implementos, sementes, defensivos e fertilizantes. Instituíram-se preceitos, os quais incluíam a incorporação da inovação tecnológica e a sua difusão pelo setor e em seus encadeamentos (Buainain, Romeiro e Guanziroli, 2003).

Para atender à inovação tecnológica, instituiçôes de pesquisa agropecuária foram constituídas à época, como a Empresa Brasileira de Pesquisa Agropecuária (Embrapa) e algumas instituiçôes estaduais, além das universidades com áreas de pesquisa voltadas para o tema. Também houve incentivo para formação de pesquisadores especialistas em estudos agropecuários; corolário desse processo, a inovação tecnológica na agropecuária brasileira teve significativo impulso, cujo resultado foi o aumento de produtividade das lavouras e da produção animal e derivados.

A fim de difundir as inovaçóes pelo vasto território brasileiro, surgiu a figura do profissional de Assistência Técnica e Extensão Rural (Ater), com formação acadêmica nas áreas de engenharia agronômica, engenharia agrícola, zootecnia, economia doméstica ou

1. DOI: http://dx.doi.org/10.38116/brua24art12

2. Pesquisadora do Programa de Pesquisa para o Desenvolvimento Nacional (PNPD) na Diretoria de Estudos e Políticas Regionais, Urbanas e Ambientais (Dirur) do Ipea; e doutora em desenvolvimento econômico pela Universidade Estadual de Campinas (Unicamp).

3. Especialista em políticas públicas na Dirur/lpea; e doutorando em geografia pela Universidade de Brasília (UnB). 
engenharia florestal. Comumente referido como extensionista, esse profissional tem como atribuiçâo orientar os agricultores sobre como utilizar as práticas e técnicas mais eficientes na produção agropecuária. Esse novo modelo de desenvolvimento agrícola foi incorporado principalmente pelos produtores rurais do segmento capitalista e, em menor escala, pelos produtores rurais do segmento atualmente conhecido como agricultura familiar (Castro e Pereira, 2017).

Assim, o objetivo deste trabalho é analisar se os produtores agrícolas brasileiros buscam orientação técnica, e quando o fazem, qual a fonte escolhida. Para isso, o trabalho está organizado em duas seçôes, além desta introdução e das conclusóes. Primeiro será apresentado um breve histórico da Ater no Brasil e, em seguida, a análise dos dados do censo agropecuário de 2017, buscando em alguns momentos comparar com o censo agropecuário de 2006 para saber a proporção de estabelecimentos que buscaram orientação técnica e qual a origem desta. Os dados estáo apresentados por região e por tipologia do estabelecimento (agricultor familiar ou agricultor não familiar).

\section{ATER NO BRASIL}

A Ater como um serviço de orientação técnica e disseminação do conhecimento aos produtores agrícolas surgiu nos Estados Unidos e na Europa no final do século XIX e início do século XX. No país norte-americano surgiram primeiramente os farmers' institutes, criados em 1839 e substituídos no século seguinte pelas instituições de Ater, que tinham caráter público, sendo supervisionadas pelo Departamento de Agricultura dos Estados Unidos (United States Department of Agriculture - USDA) (Ros, 2012).

Em meados do século XX, esse modelo começa a ser introduzido em território brasileiro. Em 1948 foi criada em Minas Gerais a primeira instituição a adotar o modelo - a Associação de Crédito e Assistência Rural (Acar) -, com o objetivo de melhorar as condiçóes sociais e econômicas da população do campo. Esta instituição seguiu o modelo norte-americano de difusão de inovações com a atribuição de oferecer assistência técnica e financeira aos produtores rurais para que adotassem as inovaçóes desenvolvidas nos institutos de pesquisa agrícola. Em outras palavras, os institutos de extensão rural tinham como função a interlocução entre os agricultores e as instituiçóes geradoras de inovação para a agropecuária.

As relaçôes estabelecidas pelos extensionistas se materializariam na forma da vinculação dos agricultores aos mercados de financiamento, insumos e comercialização. Após a criação da Acar, surgiram outras instituiçóes nos demais estados do Brasil com o mesmo modelo, oferecendo assistência técnica ao meio rural e elaborando projetos de desenvolvimento agrícola para que os agricultores tivessem acesso ao crédito rural subsidiado pelo Estado.

De acordo com Oliveira (1999), ao final da década de 1950, os serviços de Ater já se encontravam presentes na metade dos estados brasileiros, como em todos das regiôes Sudeste e Sul e expandindo-se para os estados do Nordeste (Ceará, Pernambuco, Bahia, Rio Grande do Norte e Paraíba) e Centro-Oeste (Goiás). A expansão da Acar no território nacional propiciou a institucionalizaçáo efetiva de um serviço de Ater no país, que passou a ser coordenado, em 1956, pela Associação Brasileira de Crédito e Assistência Rural (Abcar), entidade de caráter privado que congregou cada Acar segundo um modelo centralizado e vertical de orientação (Caporal, 1998 apud Oliveira, 1999).

A princípio, essas entidades não estavam sob a responsabilidade do Estado, que passou lentamente a incorporá-las às suas atribuiçôes, oferecendo suporte financeiro, e em troca exigia 
apoio ao projeto de desenvolvimento rural. Como parte deste projeto criou-se a Empresa Brasileira de Assistência Técnica e Extensão Rural (Embrater) em 1975; assim cada Acar passou a se chamar Empresa Estadual de Assistência Técnica e Extensão Rural (Emater), subordinada à Embrater. Esta empresa trabalhava em colaboração com a Embrapa, que produzia e adaptava as inovaçóes tecnológicas, enquanto a Embrater disseminava o conhecimento e a tecnologia para a rede de entidades brasileiras de assistência técnica, as quais, por sua vez, eram responsáveis por difundir as inovações tecnológicas no meio rural brasileiro.

Com a crise fiscal dos anos 1980, a capacidade do Estado ficou altamente reduzida para manter determinados serviços. Com os governos federal e estaduais sem recursos, o serviço de Ater ofertado pelo Estado foi impactado negativamente pelo processo de ajuste fiscal, o que resultou no seu gradativo desmonte e menor capacidade de atuaçáo. Como este serviço é demandado em grande medida pelos pequenos produtores e agricultores familiares, estes foram os mais prejudicados com a extinção da Embrater em 1989.

Paralelamente, outras fontes de orientação técnica cresceram ao longo dos anos, como as próprias empresas integradoras, que vendem insumos tecnológicos e em troca oferecem assistência técnica para utilizar os produtos e aplicá-los nos cultivos. Também houve o crescimento da participação da assistência própria do estabelecimento, em função da grande quantidade e da alta qualidade do ensino agrícola no Brasil, que ao longo dos anos vem capacitando milhares de profissionais para atuar no setor. Com isso, grandes propriedades começaram a contratar seus próprios funcionários para atender às necessidades da lavoura. E, por fim, surgiram as cooperativas, com grande incidência no Sul do Brasil, que possuem profissionais especializados para atender os cooperados.

Desse modo, o modelo de Ater ofertado pelo Estado, apesar de ter sofrido com a diminuição de recursos, foi compensado pelo aumento de outros tipos de orientação técnica, capazes de suprir as necessidades do produtor rural. Assim, a discussão sobre a reestruturação do sistema de assistência técnica pública tem que considerar onde este se faz necessário, levando em conta a localização e a tipologia do estabelecimento, para que se oferte um serviço adequado e atenda às reais necessidades dos produtores rurais.

\section{ATER VIA CENSO AGROPECUÁRIO DE 2017}

Para ilustrar o que foi exposto na seção anterior - a sutil redução do recebimento de orientação técnica pelos estabelecimentos agropecuários brasileiros nos últimos anos, principalmente em relaçáo à assistência técnica de origem governamental -, esta seçáo apresenta dados do censo agropecuário de 2017 sobre o recebimento de orientação técnica e a origem desta. As informaçôes estấo apresentadas por regiôes e por estado, em casos relevantes, além da desagregação por tipologia do estabelecimento - agricultura familiar e não familiar.

Somente $20,2 \%$ dos estabelecimentos do Brasil declararam ter recebido algum tipo de orientação técnica em 2017. Houve uma leve redução em relação a 2006, quando foi de $22,1 \%$. A região Sul possui a maior proporção de estabelecimentos recebendo algum tipo de orientaçáo técnica $(48,6 \%)$, e é a única regiáo que apresentou crescimento ante o censo de 2006, quando foi de 48,4\%. O Sudeste apresentou 30,7\% em 2006 e 28,6\% de estabelecimentos atendidos em 2017. O Centro-Oeste aparece em terceiro lugar, com 23,7\% de seus estabelecimentos com orientação, porém em 2006 havia 30\% dos casos. A região Norte apresentou 15,5\% de orientaçáo em 2006 e caiu para 10,4\% em 2017. E a regiáo Nordeste aparece em último, com 8,4\% em 2006 e 8,2\% em 2017, a menor proporção de assistência do Brasil. 
O mapa 1 mostra a proporção de estabelecimentos por município que recebeu algum tipo de orientação técnica, segundo o censo agropecuário de 2017. A faixa de cor escura, que representa acima de 50\% dos estabelecimentos com orientação técnica, aparece sobretudo nas regiôes Sudeste e Sul. Municípios de Mato Grosso, Mato Grosso do Sul e Goiás também se destacam.

\section{MAPA 1}

Estabelecimentos agropecuários que receberam orientação técnica - censo agropecuário de 2017

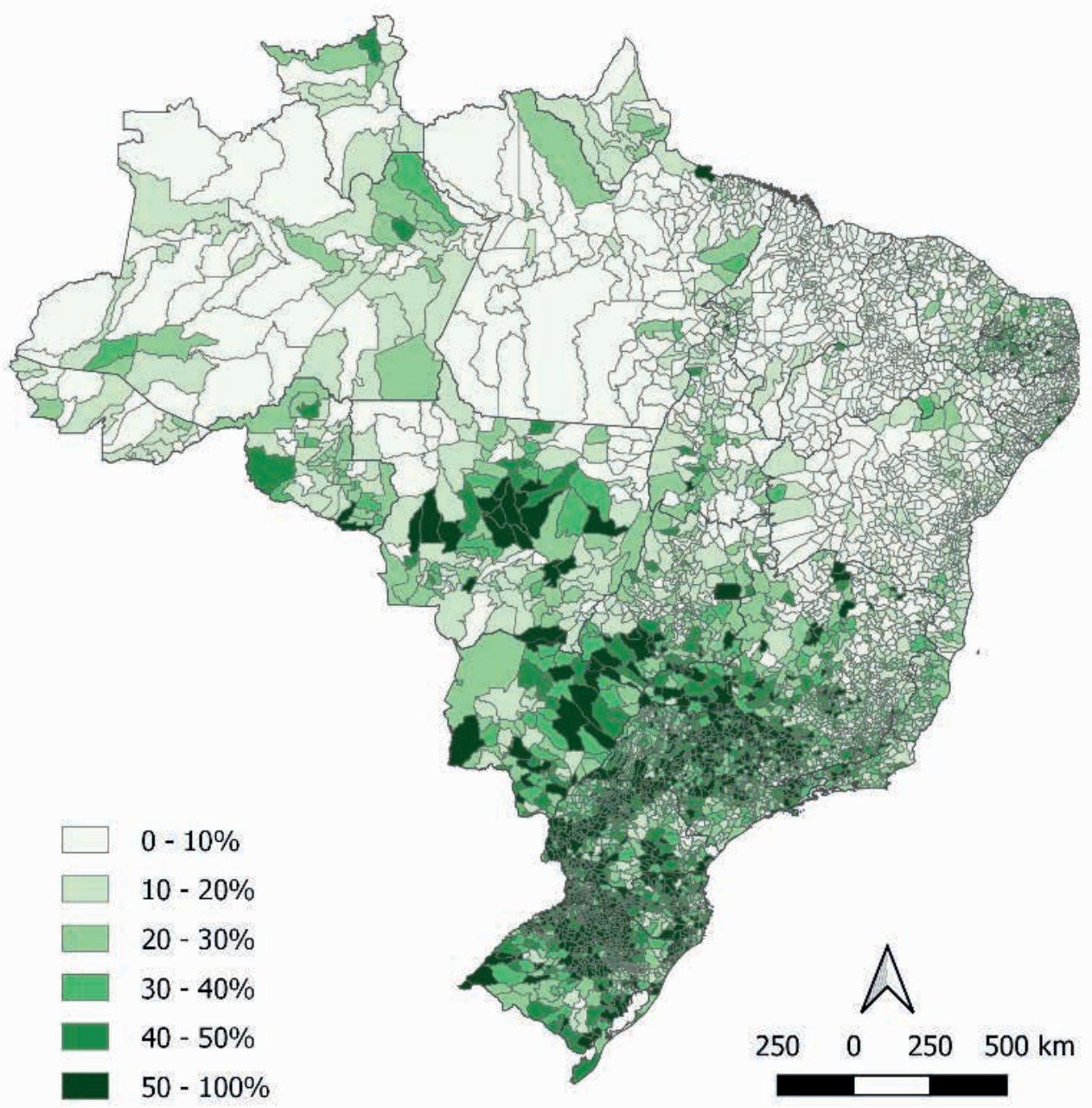

Fonte: IBGE (2019)

Obs.: Figura cujos leiaute e textos não puderam ser padronizados e revisados em virtude das condições técnicas dos originais (nota do Editorial

O conhecimento apenas dos dados gerais de orientação técnica, contudo, é pouco explicativo sobre o que acontece nos estabelecimentos agropecuários. Para tornar esta análise mais substantiva, os dados serão desagregados primeiramente pelo tipo de orientação técnica recebida para comparar os censos agropecuários de 2006 e 2017, e em um segundo momento desagregados pela tipologia do estabelecimento, agricultura familiar e não familiar, para analisar entre esses dois grupos qual origem de orientação técnica é mais recorrente segundo o censo agropecuário de $2017 .{ }^{4}$

4. A desagregação por tipologia de estabelecimento (agricultura familiar e não familiar) não estava disponível para o censo agropecuário de 2006. Deste modo, a comparação entre os dois censos utilizou os dados agregados dos estabelecimentos. 
Pelo tipo de orientação técnica recebida, o censo agropecuário de 2017 apresentou as seguintes fontes: governamental (federal, estadual ou municipal), própria (do próprio produtor), cooperativas, empresas integradoras, empresas privadas, organizaçóes não governamentais (ONGs), Sistema $\mathrm{S}$ e outras. Importante enfatizar que um estabelecimento agropecuário pode receber mais de um tipo de orientação técnica, por exemplo, do governo estadual e de cooperativas.

Da orientação técnica recebida pelos estabelecimentos agropecuários brasileiros em 2017, 37,8\% foram fornecidos pelas instituiçóes de orientação técnica governamental, 30,9\% própria ou de produtores, $24,5 \%$ de cooperativas, $13,2 \%$ de empresas integradoras, entre outras em menor quantidade. Analisando a demanda pelas distintas fontes de orientação técnica entre os censos de 2006 e 2017, nota-se queda em todas as regióes da orientação técnica governamental (tabela 1). A regiáo que apresentou maior redução foi Centro-Oeste, de 36\% para $25 \%$. O Nordeste, apesar da redução, ainda utiliza em grande medida este serviço $60 \%$ entre aqueles que a utilizam. Entre as Unidades Federativas (UFs), houve aumento da orientação pública no Amapá, de $77 \%$ para $87 \%$; Ceará, de $82 \%$ para $85 \%$; Paraíba, de $57 \%$ para $77 \%$; e Distrito Federal, de $86 \%$ para $88 \%$. Todos os demais estados apresentaram redução neste tipo de orientação.

TABELA 1

Origem da orientação técnica recebida pelos estabelecimentos agropecuários - censos agropecuários de 2006 e $2017^{1}$

(Em \%)

\begin{tabular}{|c|c|c|c|c|c|c|c|c|}
\hline & $\begin{array}{l}\text { Governo } \\
(F, E, M)\end{array}$ & $\begin{array}{l}\text { Própria ou } \\
\text { produtor }\end{array}$ & Cooperativas & $\begin{array}{c}\text { Empresas } \\
\text { integradoras }\end{array}$ & $\begin{array}{l}\text { Empresas } \\
\text { privadas }\end{array}$ & ONGs & Sistema S & Outras \\
\hline \multicolumn{9}{|c|}{ Censo agropecuário de 2006} \\
\hline Brasil & 42,9 & 21,9 & 19,7 & 13,4 & 7,4 & 0,6 & - & 2,7 \\
\hline Norte & 72,9 & 18,3 & 6,0 & 1,6 & 2,9 & 0,5 & - & 0,8 \\
\hline Nordeste & 61,9 & 25,7 & 3,6 & 2,6 & 4,2 & 1,8 & - & 2,8 \\
\hline Sudeste & 42,0 & 30,8 & 18,7 & 4,7 & 6,8 & 0,4 & - & 4,1 \\
\hline Sul & 32,3 & 12,5 & 31,1 & 26,5 & 8,4 & 0,3 & - & 2,0 \\
\hline Centro-Oeste & 36,0 & 37,7 & 9,6 & 5,5 & 15,1 & 0,4 & - & 2,5 \\
\hline \multicolumn{9}{|c|}{ Censo agropecuário de 2017} \\
\hline Brasil & 37,8 & 30,9 & 24,5 & 13,2 & 2,8 & 0,8 & 0,7 & 5,1 \\
\hline Norte & 66,7 & 24,3 & 3,7 & 2,7 & 1,4 & 1,3 & 1,2 & 4,5 \\
\hline Nordeste & 60,0 & 23,5 & 7,7 & 2,1 & 1,1 & 3,0 & 1,0 & 6,9 \\
\hline Sudeste & 32,0 & 41,5 & 23,9 & 5,1 & 1,7 & 0,4 & 0,7 & 6,4 \\
\hline Sul & 29,9 & 23,6 & 37,4 & 26,6 & 4,3 & 0,2 & 0,4 & 3,6 \\
\hline Centro-Oeste & 25,0 & 53,2 & 16,1 & 6,0 & 3,7 & 0,3 & 1,8 & 3,9 \\
\hline
\end{tabular}

Fonte: IBGE (2019).

Nota: ${ }^{1}$ Cada estabelecimento agropecuário pode ter recorrido a mais de uma fonte de orientação técnica. Obs.: F - federal; E - estadual; M - municipal.

Em contrapartida, a orientação técnica proveniente de cooperativas, do próprio produtor e de empresas integradoras aumentou em praticamente todas as regiôes. A orientação do próprio produtor cresceu de $22 \%$ para $31 \%$ no Brasil. Subiu sobremaneira na regiáo Sul, de $12,5 \%$ para 23,6\%; no Centro-Oeste, de 38\% para 53\%; e no Sudeste, de 31\% para $41,5 \%$. A única região que apresentou redução neste tipo de orientação foi o Nordeste, de $25,7 \%$ para $23,5 \%$. 
O aumento no uso deste tipo de orientação cresceu substancialmente em muitos estados, como Tocantins, de $23 \%$ para $38 \%$, e Piauí, de $21 \%$ para $30 \%$. No Centro-Oeste houve aumento neste tipo de orientaçáo, exceto para o Distrito Federal, que reduziu de $16 \%$ para $10 \%$.

As cooperativas ganharam maior participação, aumentando de $19,7 \%$ para $24,5 \%$ no Brasil, com decréscimo somente na região Norte, de $6 \%$ para 3,7\%. No Nordeste as cooperativas e as ONGs foram as únicas fontes de orientação que apresentaram aumento de participação para o conjunto da regiáo. Ainda em relação às cooperativas, elas cresceram neste serviço no Matopiba, ${ }^{5}$ em específico no Maranhão, de 1,4\% para 4\%; no Piauí, de 1,7\% para 7\%; e na Bahia, de $4 \%$ para $14 \%$. Também chama a atençáo o crescimento deste tipo de fonte no Distrito Federal, que saltou de 1,5\% para 5,4\%. Em todos os estados da região Sudeste, exceto Rio de Janeiro, as cooperativas estão orientando mais os produtores, bem como na região Sul. Como exemplo, Santa Catarina saiu de 20\% para 33\%. No Centro-Oeste, essa fonte praticamente dobrou de participação em todos os estados.

Com participação menor, porém não menos importante, estão as empresas integradoras, com modesta redução de 13,4\% para 13,2\%. Entre as regióes, cresceu levemente, com exceção do Nordeste, de 2,6\% para 2,1\%. Porém, nesta região, os estados do Matopiba aumentaram a demanda por esta orientaçáo. Tocantins de 0,9\% para 2,5\%; Maranhão de $3,7 \%$ para $4,3 \%$; e Bahia de 3\% para 3,6\%.

A diminuição da participação de cada Emater em grande parte do Brasil é fruto da redução dos investimentos públicos nesta política, em virtude da crise fiscal dos estados. Como mencionado na seção anterior, com o fim da Embrater a situação da assistência técnica pública ficou dependente dos estados, que apresentam variabilidade na oferta deste serviço aos produtores. Ademais, a forma como está estruturada a agricultura em cada regiâo também determina o tipo de orientaçáo recebida. A regiáo Sul é historicamente formada por pequenos produtores cooperados (Farias, 2015), o que explica a maior participação das cooperativas que ofertam orientação técnica.

A região Nordeste responde pela maioria dos agricultores familiares brasileiros, para os quais cada Emater é direcionada (Castro e Pereira, 2017), explicando a participação da assistência técnica pública nesta regiáo. A parcela de orientação própria ou de cooperativas aparece nos espaços mais dinâmicos, como Matopiba, regiáo formada por grandes propriedades voltadas para a produção de grãos (Buainain, Garcia e Vieira Filho, 2018).

O Centro-Oeste apresenta a maior participação de orientação própria em função da proeminente produção de grãos voltada para o mercado externo. A estrutura de produção é grandiosa, com profissionais especializados dentro da fazenda, prescindindo cada vez mais de orientaçóes externas. Destaca-se a exceção do Distrito Federal, que apresentou alta participação da Emater como fonte de orientação técnica. Isto possivelmente se deve entre outros motivos ao bom trabalho da empresa, que já havia sido certificada em 2015 pelo Ministério do Desenvolvimento Agrário (MDA) pelas boas práticas agrícolas (Castro e Pereira, 2017).

Analisando apenas os agricultores familiares, observa-se o menor acesso à orientaçáo técnica entre estes - $18 \%$ para o conjunto brasileiro desses agricultores. No Centro-Oeste apenas $16,4 \%$ do total de agricultores familiares recorreu a algum tipo de orientação.

5. Região formada pelos estados do Maranhão, Tocantins, Piauí e Bahia. 
Nas demais regiôes também há menor uso de orientação técnica por esse tipo de agricultor, $8,8 \%$ nos estabelecimentos do Norte; $7,3 \%$ no Nordeste; e $24,5 \%$ no Sudeste. A exceção se encontra na regiáo Sul, com maior uso de orientação técnica entre os agricultores familiares $(48,9 \%)$ do que em relação ao todo. Entre os estabelecimentos da agricultura não familiar, $27 \%$ recorreram a algum tipo de orientação técnica no censo agropecuário de 2017 , ou seja, há maior informação técnica neste tipo de estabelecimento.

Assim, entre aqueles estabelecimentos agropecuários que receberam algum tipo de orientação técnica, há distinções entre os de agricultura familiar e os de agricultura não familiar. Entre os primeiros, que receberam orientação técnica, $18,2 \%$ do total, a governamental foi preponderante (43\%), seguida de cooperativas (26\%). Já entre os estabelecimentos de agricultura não familiar que receberam orientação técnica, a preponderância foi por orientação própria ou do próprio produtor $(51,3 \%)$. Na região Nordeste, a participação governamental é ainda mais significativa, $66,8 \%$ entre estabelecimentos de agricultura familiar que receberam orientação, e também nos de agricultura não familiar, com $43,6 \%$, porém aqui a orientação própria ou do próprio produtor também apresentou forte participação, 42,5\% (tabela 2).

TABELA 2

Origem da orientação técnica recebida segundo tipologia do estabelecimento - agricultura familiar ou não familiar (2017)

(Em \%)

\begin{tabular}{|c|c|c|c|c|c|c|c|c|}
\hline & $\begin{array}{l}\text { Governo } \\
(F, E, M)\end{array}$ & $\begin{array}{l}\text { Própria ou do } \\
\text { próprio produtor }\end{array}$ & Cooperativas & $\begin{array}{c}\text { Empresas } \\
\text { integradoras }\end{array}$ & $\begin{array}{c}\text { Empresas } \\
\text { privadas }\end{array}$ & ONGS & Sistema S & Outras \\
\hline \multicolumn{9}{|c|}{ Agricultura familiar - não } \\
\hline Brasil & 25,5 & 51,3 & 21,8 & 6,9 & 3,1 & 0,6 & 0,8 & 4,8 \\
\hline Norte & 44,3 & 48,0 & 3,1 & 3,1 & 2,3 & 0,6 & 1,1 & 4,8 \\
\hline Nordeste & 43,6 & 42,5 & 5,5 & 2,6 & 1,5 & 2,2 & 1,1 & 6,6 \\
\hline Sudeste & 21,3 & 56,9 & 23,1 & 5,1 & 2,0 & 0,3 & 0,6 & 5,5 \\
\hline Sul & 21,9 & 41,9 & 38,1 & 12,8 & 4,9 & 0,2 & 0,5 & 3,4 \\
\hline Centro-Oeste & 13,0 & 68,6 & 14,1 & 6,3 & 4,2 & 0,2 & 1,2 & 3,8 \\
\hline \multicolumn{9}{|c|}{ Agricultura familiar - sim } \\
\hline Brasil & 43,4 & 21,7 & 25,7 & 16,0 & 2,6 & 0,9 & 0,7 & 5,2 \\
\hline Norte & 76,1 & 14,2 & 3,9 & 2,5 & 1,0 & 1,6 & 1,2 & 4,4 \\
\hline Nordeste & 66,8 & 15,6 & 8,5 & 1,9 & 0,9 & 3,4 & 1,0 & 7,0 \\
\hline Sudeste & 38,9 & 31,6 & 24,4 & 5,2 & 1,5 & 0,4 & 0,7 & 7,1 \\
\hline Sul & 32,1 & 18,6 & 37,2 & 30,4 & 4,1 & 0,2 & 0,4 & 3,7 \\
\hline Centro-Oeste & 39,8 & 34,0 & 18,6 & 5,5 & 3,1 & 0,4 & 2,5 & 4,1 \\
\hline
\end{tabular}

Fonte: IBGE (2019).

Obs.: F - federal; E - estadual; M - municipal.

O destaque é a diferença desta distribuição entre as regiôes pelo tipo de orientação recebida. As regióes Norte e Nordeste têm semelhanças quanto à origem da orientação recebida e à tipologia do estabelecimento. Para os estabelecimentos de agricultura náo familiar que receberam orientação técnica, a preponderância é de orientação própria e governamental no Norte e Nordeste, cerca de $45 \%$ para ambas as fontes. Entretanto, para as UFs de maior dinamismo agrícola na regiáo Norte, como Tocantins e Pará, que possuem muitos estabelecimentos pecuários e também com produção de soja, entre outros grãos, a orientação técnica própria, típica de grandes propriedades, é predominante, 59,4\% e 57,2\%, respectivamente. Ainda nos estabelecimentos de agricultura não familiar que receberam orientação, também ocorre 
a maior participação de orientação própria nos estados de Pernambuco, 46,4\%; Rio Grande do Norte, 48,9\%; Piauí, 48,8\%; Maranhão, 56,8\%; e Bahia, 51,5\%.

Entre os poucos estabelecimentos de agricultura familiar que recorreram a algum tipo de orientação técnica, 76\% utilizam orientação governamental no Norte e $67 \%$ dos nordestinos. Entre os que receberam orientaçáo, a orientaçáo própria aparece em 14\% dos estabelecimentos do Norte e 15,6\% do Nordeste. Esses valores são os maiores para a orientaçáo governamental entre todas as cinco regiôes brasileiras, ou seja, os estabelecimentos familiares do Norte e Nordeste são os que mais utilizam, em termos relativos, a orientação técnica oriunda do governo.

Na região Sudeste, para os estabelecimentos de agricultura não familiar que receberam orientação, observa-se a predominância de orientação própria $(56,9 \%)$, seguida de cooperativas $(23,1 \%)$. O Espírito Santo apresenta a menor proporção de orientação técnica própria da regiấo $(46,1 \%)$, seguida de orientação governamental $(28,6 \%)$ e cooperativas $(22,2 \%)$. Por sua vez, a orientação própria se destaca no Rio de Janeiro (60\%), onde também há maior orientação governamental da região (34,3\%). Em São Paulo, quase 60\% da orientação técnica é de origem própria, seguida de cooperativas (27\%), enquanto a assistência pública foi mencionada em $12,8 \%$ dos estabelecimentos.

Entre os estabelecimentos de agricultura familiar que receberam orientação técnica, a governamental é predominante no Sudeste $(38,9 \%)$, não obstante a orientação própria ocorrer em número considerável de estabelecimentos (31,6\%). Em São Paulo, mesmo entre as propriedades de agricultura familiar, a orientação técnica própria é de maior ocorrência (36\%). A orientação governamental é predominante nos demais estados (Minas Gerais, 41\%; Espírito Santo, 38,3\%; Rio de Janeiro, 48\%). As cooperativas são fonte importante de orientação nas propriedades do Espírito Santo (32\%). No geral, há relativo equilíbrio entre a orientação pública, própria e de cooperativas nos estabelecimentos da agricultura familiar do Sudeste.

A regiáo Sul se destaca pela significativa participação do cooperativismo na orientação técnica, tanto nas propriedades familiares como nas não familiares que receberam orientação técnica, sendo $37 \%$ e $38 \%$, respectivamente. Nestas últimas, a orientação própria é predominante (41,9\%), e a governamental aparece em terceiro lugar, com $21,9 \%$. Porém, entre as UFs, o Paraná possui maior participaçáo de cooperativas na orientação técnica dos produtores não familiares $(51,2 \%)$ e a orientação própria vem em seguida (37\%). No Rio Grande do Sul há o predomínio da orientação técnica própria (50\%), seguida das cooperativas (29\%). E Santa Catarina surge como o estado sulista em que as propriedades não familiares fazem mais uso da assistência pública $(38 \%)$.

Entre as propriedades familiares da região Sul que receberam orientação, a governamental aparece em segundo lugar (32\%). Interessante que os estabelecimentos de agricultura familiar no Paraná recorrem em maior medida às cooperativas (44\%) do que à orientação pública (24,5\%). No Rio Grande do Sul a orientaçáo pública predomina (35\%) e as cooperativas também (34\%). Em Santa Catarina a situação é parecida com o Rio Grande do Sul, predomínio similar entre orientação governamental e cooperativas - 37\% e 34\%.

O Centro-Oeste apresenta comportamento distinto, em que a orientação própria é predominante nos estabelecimentos de agricultura não familiar que receberam orientação $(68,6 \%)$, seguida de cooperativas (14\%) e a menor participação de todas as regióes brasileiras na orientação governamental (13\%). Em Mato Grosso, Mato Grosso do Sul e Goiás a 
orientação própria é cerca de $70 \%$; enquanto no Distrito Federal ela foi apontada como fonte de informaçôes em apenas $18 \%$ dos estabelecimentos não familiares que receberam orientação. As cooperativas aparecem em maior medida em Goiás (20\%) e Mato Grosso do Sul (15\%). A orientação governamental surge em cerca de 10\% dos estabelecimentos de Mato Grosso, Mato Grosso do Sul e Goiás e em $80 \%$ dos estabelecimentos não familiares do Distrito Federal que receberam alguma orientação.

Entre os agricultores familiares do Centro-Oeste que recorreram à orientação, houve maior uso da governamental (40\%) e da própria (34\%). Em Goiás, os agricultores familiares com orientação se valem em maior medida da orientação própria (42\%), governamental (26\%) e cooperativas (25\%). Em Mato Grosso do Sul observa-se maior ocorrência da orientação pública $(53 \%)$ e própria (24\%) entre aqueles com alguma orientação. Em Mato Grosso também se observa maior orientação própria mesmo entre os agricultores familiares (38\%), seguida da orientação governamental (36\%). A maior contribuição da assistência pública de todas as UFs brasileiras se encontra no Distrito Federal - 96\% dos estabelecimentos familiares que afirmaram utilizar algum tipo de orientação recorreram à Emater do Distrito Federal para obter orientação.

\section{CONSIDERAÇÕES FINAIS}

A redução na orientação técnica recebida pelos estabelecimentos agrícolas brasileiros entre os dois censos foi sutil, de 22,1\% para 20,2\%. Essa redução pode ser atribuída em maior medida à diminuição da participação das empresas públicas de assistência técnica em todas as regiôes, porém com crescimento em nível estadual para Amapá, Ceará, Distrito Federal e Paraíba. Em contrapartida, aumentou o recebimento de orientação proveniente do próprio produtor e de cooperativas, principalmente nos espaços que contam com agricultura mais dinâmica, como Centro-Oeste, Sul e Matopiba.

Ao desagregar entre os estabelecimentos de agricultura familiar e não familiar, observa-se que o segundo grupo demanda mais este tipo de serviço (27\%), ante $18 \%$ dos estabelecimentos familiares. Entre as regióes, há muita disparidade, fruto da intensidade e do tipo das atividades agrícolas em cada região, bem como da estrutura do serviço de Ater em cada UF. O histórico de associativismo também influenciou os resultados. Na região Sul, as cooperativas têm grande presença na orientação técnica dos produtores. A região Centro-Oeste chama a atenção para o predomínio da orientação técnica própria, em virtude das grandes propriedades que contam com profissionais especializados. A exceção se encontra no Distrito Federal, onde há maior participação da assistência pública aos produtores. Norte e Nordeste são as áreas mais dependentes da orientação técnica de Emater, pois é onde se encontra a maioria dos estabelecimentos familiares.

Os dados dos censos agropecuários de 2006 e 2017, analisados neste artigo, indicam a considerável importância da Ater pública em todas as regióes (mesmo naquelas em que não é predominante), principalmente entre os estabelecimentos da agricultura familiar. Esta importância justifica a maior discussão sobre este serviço e, possivelmente, a sua ampliação. Este artigo não focou no debate acerca da necessidade de ampliação do serviço de Ater, o qual será objeto de estudo em trabalhos futuros, procurando relacionar os dados aqui apresentados com possíveis explicações sobre a menor oferta de Ater pelas UFs brasileiras e o crescimento da participação das outras fontes como cooperativas e orientação própria.

Além da questão da Ater pública, a sua qualidade em todas as fontes é importante com relação à eficiência produtiva (técnica, econômico-financeira, ambiental etc.) dos 
estabelecimentos agropecuários brasileiros. Os dados do censo agropecuário de 2017 não permitem fazer inferências sobre essa questão, e sugere-se ao Instituto Brasileiro de Geografia e Estatística (IBGE) que avalie a viabilidade de inclusão de perguntas nesse sentido em futuras iteraçôes da avaliação censitária agropecuária.

\section{REFERÊNCIAS}

BUAINAIN, A. M.; GARCIA, J. R.; VIEIRA FILHO, J. E. R. A economia agropecuária do Matopiba. Revista Estudos Sociedade e Agricultura, v. 26, n. 2, jun./set. 2018.

BUAINAIN, A. M.; ROMEIRO, A. R.; GUANZIROLI, C. Agricultura familiar e o novo mundo rural. Sociologias, Porto Alegre, ano 5, n. 10, p. 312-347, jul./dez. 2003.

CASTRO, C. N.; PEREIRA, C. N. Agricultura familiar, assistência técnica e extensão rural e a política nacional de Ater. Brasília: Ipea, out. 2017. (Texto para Discussão, n. 2343).

FARIAS, F. R. A dinâmica geoeconômica do cooperativismo agropecuário do Sul do Brasil. 2015. Tese (Doutorado) - Centro de Filosofia e Ciências Humanas, Universidade Federal de Santa Catarina, Florianópolis, 2015.

IBGE - INSTITUTO BRASILEIRO DE GEOGRAFIA E ESTATÍSTICA. Censo agropecuário 2017. Rio de Janeiro, 2019. Disponível em: <https://sidra.ibge.gov.br/pesquisa/censo-agropecuario/ censo-agropecuario-2017>. Acesso em: 15 jul. 2020.

OLIVEIRA, M. M. As circunstâncias da criação da extensão rural no Brasil. Cadernos de Ciência e Tecnologia, Brasília, v. 16, n. 2, p. 97-134, 1999.

ROS, C. A. Gênese, desenvolvimento, crise e reformas nos serviços públicos de extensão rural durante a década de 1990. Mundo Agrário, La Plata, v. 13, n. 25, 2012.

VIEIRA FILHO, J. E. R.; FISHLOW, A. Agricultura e indústria no Brasil: inovação e competitividade. Brasília: Ipea, 2017. 305 p. 